\title{
Cerebellopontine Angle Embryonal Tumor, Not Otherwise Specified
}

National Cancer Institute

\section{Source}

National Cancer Institute. Cerebellopontine Angle Embryonal Tumor, Not Otherwise

Specified. NCI Thesaurus. Code C5436.

A central nervous system embryonal tumor, not otherwise specified arising from the cerebellopontine angle of the infratentorial brain. 